\title{
PERENCANAAN DAN PENJADWALAN PRODUKSI DENGAN MENGUNAKAN METODE TRANSPORTASI GUNA MENINGKATKAN PROFIT
}

\author{
Ayudina Puji $\mathbf{E}^{1}$, Junaedi Iskandar ${ }^{2}$
}

\begin{abstract}
The first step of implementing the planning and schedulling of production using transportation method is forecast the demand that count the number of demand that depend on the trend of data. Recording to the analysis, the fix method which appropiate with trend of data is moving average, single exponenthial and double exponential method. The next step is mix data based on the forecasting result that have conversed into hours, and change cost into hours. The last step using those data into 85 program to get a production plan and cost of planning result. From the final analysis can find decreasing cost after implementing transportation method about Rp.31.765.280,- or 7,27\% off of the overall cost.
\end{abstract}

\section{Key Words : Schedulling, transportation, profit}

\section{PENDAHULUAN}

Untuk itu perlu dibuat suatu strategi yang tepat untuk mengantisipasi fluktuasi permintaan yaitu dengan penentuan alokasi sumber yang tepat agar permintaan tersebut dapat terpenuhi. Pengalokasian sumber yang tepat sangat penting untuk mengantisipasi lonjakan permintaan apabila produksi tidak mampu menyesuaikan secara cepat terhadap permintaan. Sehingga apabila antara jumlah produksi dan jumlah permintaan seimbang maka biaya-biaya lain yang tidak perlu dapat ditekan, sehingga nantinya diharapkan dapat menaikkan profit atau laba perusahaan.

Strategi yang dapat dilakukan adalah meningkatkan efisiensi produksi dengan membuat perencanaan produksi yang sebaik mungkin, yaitu dengan menggunakan metode Transportasi. Rencana produksi yang dilakukan menggunakan metode Transportasi bertujuan untuk mengoptimalkan pengalokasian sumber-sumber yang ada sesuai dengan kebutuhan . Sehingga apabila sumbersumber yang ada tersebut dapat memenuhi semua kebutuhan maka rencana produksi yang baik akan dapat diperoleh.

Alasan utama dipakainya metode transportasi untuk merencanakan produksi dikarenakan kurang baiknya pengalokasian sumber-sumber yang ada sehingga menyebabkan kerugian pada perusahaan.

\section{TINJAUAN PUSTAKA}

\section{METODE PERAMALAN}

Metode peramalan adalah suatu cara memperkirakan secara kuantitatif apa yang akan terjadi dimasa depan berdasarkan data-dãta relevan dimasa yang lalu, maka peramalan ini digunakan dalam peramalan yang obyektif.

1) Dosen Jurusan Teknik Industri \&o 2) Alumni Jurusan Teknik Industri FT. Universitas Mubammadiyah Malang 
a.Simple moving Average

Digunakan untuk peramalan apabila data aktual yang digunakan dalam peramalan diambil selama periode yang lama. Persamaannya adalah :

$$
\mathrm{y}_{\mathrm{t}}{ }_{\mathrm{t}}=\frac{y_{t-1}+y_{t-2}+y_{t-3}+\ldots y_{t-n}}{n}
$$

Dimana ;

$$
\mathrm{n} \quad=\text { Adalah jumlah periode yang }
$$

digunakan sebagai dasar peramalan.

$$
y^{\prime} t=\text { Ramalan permintaan untuk }
$$
periode $\mathrm{t}$

$\mathrm{yt}=$ Permintaan aktual pada periode $\mathrm{t}$

$\mathrm{yt}-\mathrm{l}=$ Permintaan sebelum periode $\mathrm{t}$

\section{b. Single Eksponensial Smoothing}

Digunakan apabila data yang digunakan mempunyai trend yang tidak pasti. Persamaannya adalah :

$$
\mathrm{F}(0)=\mathrm{A}(1)
$$

$\mathrm{F}^{\prime} \mathrm{t}=\alpha \mathrm{At}+(1 \alpha) \mathrm{F}^{\prime} \mathrm{t}-1$

$\mathrm{F}(\mathrm{t}+\tau)=\mathrm{F}(\mathrm{t})$

\section{Dimana:}

F't = Perkiraan permintaan pada periode $\mathrm{t}$

$\alpha=$ Nilai $(0<\alpha<1)$ yang ditentukan secara subyektif

$\mathrm{Ft}=\mathrm{At}=$ Permintaan aktual periode $\mathrm{t}$

$\mathrm{F}$ ' $\mathrm{t}-1$ = Perkiraan permintaan pada periode $\mathrm{t}$

\section{Model Double Eksponensial Smoothing}

Digunakan apabila data yang digunakan mempunyai pola yang kecenderungan pasti. Persamaannya adalah :

$$
\begin{aligned}
& \mathrm{F}(0)=\mathrm{F}^{\prime}(0)=\mathrm{A}(1) \\
& \mathrm{Ft}=\propto \mathrm{A}_{\mathrm{t}}+(1-\propto) \mathrm{F}_{\mathrm{t}-1} \\
& \mathrm{~F}^{\prime} \mathrm{t}=\propto \mathrm{F}_{\mathrm{t}}+(1-\propto) \mathrm{F}_{\mathrm{t}-1}^{\prime} \\
& \mathrm{A}^{\prime} \mathrm{t}=\mathrm{F}^{\prime} \mathrm{t} \\
& \mathrm{F}(\mathrm{t}+\tau)=\mathrm{F}^{\prime}(\mathrm{t})
\end{aligned}
$$

\section{Dimana:}

$$
\begin{aligned}
& \propto=\text { Parameter smoothing } \\
& \beta=\text { Parameter kecenderungan } \\
& \mathrm{A}_{\mathrm{t}}=\text { Data aktual pada periode } \mathrm{t} \\
& \mathrm{A}^{\prime}{ }_{\mathrm{t}}=\mathrm{F}^{\prime} \mathrm{t}=\text { Peramalan periode } \mathrm{t} \\
& \mathrm{F}_{\mathrm{t}-1}^{\prime}=\text { Data peramalan sebelum periode } \mathrm{t} \\
& (\text { Sumber: Yih-Long Chang, 1993, hal } 343 \text { ) }
\end{aligned}
$$

\section{TAHAP PENJADWALAN PRODUKSI}

Pada dasarnya metode transportasi menurut S. Pangestu, T. Hani Handoko dapat diselesaikan dengan algoritma:

- VAM (vogel' approximation menthod)

- NCR

- MODI

- $\quad$ Least Cost

- DLL

Metode transportasi merupakan metode linier programming yang telah disederhanakan. Metode ini memberikan hasil yang optimal, dengan syarat masalah yang akan diselesaikan equivalen dengan masalah transportasi. Masalah perencanaan agregat harus diformulasikan sebagai berikut:

1. Kapasitas produksi dan permintaan dinyatakan dalam satuan yang sama.

2. Total kapasitas sama dengan total permintaan dalam horison yang sama. Jika keadaan ini tidak terpenuhi maka harus dibuat kapasitas atau permintaan buatan atau Dummy dengan biaya nol per unit, sehingga sistem jadi seimbang.

3. Semua hubungan biaya linear. Sasarannya adalah meminimumkan biaya produksi dan biaya permintaan. 
Fungsi tujuan dari formulasi dengan transportasi adalah sebagai berikut :

$$
\begin{aligned}
& \quad \text { Minimumkan } \mathrm{z}=\sum_{i=1}^{m} \sum_{j=1}^{n} C_{i j} X_{i j} \\
& \text { Dengan batasan } \sum_{j=1}^{n} X_{i j} \leq \mathrm{a}_{\mathrm{I}}, \mathrm{I}=1,2, \ldots, \mathrm{m} \\
& \sum_{i=1}^{m} X_{i j} \geq \mathrm{b}_{\mathrm{j}}, \mathrm{j}=1,2, \ldots, \mathrm{n} \\
& \mathrm{a}_{\mathrm{i}} \geq 0 \\
& \mathrm{~b}_{\mathrm{j}} \geq 0 \\
& \mathrm{X}_{\mathrm{ij}} \geq 0, \text { untuk semua } \mathrm{I} \text { dan } \mathrm{j} \\
& \mathrm{Dimana} \\
& \mathrm{Z}=\text { Fungsi tujuan. } \\
& \mathrm{C}_{\mathrm{ij}}=\text { Biaya transportasi adri sumber } \mathrm{I} \text { ke } \\
& \quad \text { tujuan } \mathrm{j} \\
& \mathrm{X}_{\mathrm{ij}}=\text { Jumlah unit yang dialokasikan dari } \\
& \mathrm{a}_{\mathrm{I}}=\text { Kapasitas sumber } \mathrm{i} \\
& \mathrm{b}_{\mathrm{j}}=\text { Jumlah permintaan pada tujuan } \mathrm{j}
\end{aligned}
$$

\section{Langkah-langkah penyelesaian} masalah perencanaan agregat dengan transportasi menurut S. C. Narasimhan adalah sebagai berikut:

1. Didefinisikan jenis alternatif yang akan disertakan dalam kegiatan produksi beserta kapasitasnya. Alternatif produksi itu dapat berupa:

- Regular Time (RTt) dengan kapasitas per periode $\mathrm{Lt}$

* Over Time (OTt) dengan kapasitas Mt

* Inventory (It) dengan kapasitas tidak terbatas
Pada metode transportasi tidak diperhitungkan alternatif subcontracting

2. Tentukan biaya per unit

$$
\begin{aligned}
& \text { Biaya Regular Time (r) } \\
& \text { Biaya Over Time (v) } \\
& \text { Biaya Simpan }(\mathrm{Ch})
\end{aligned}
$$

3. Jumlahkan semua kapasitas yang tersedia selama satu horison termasuk inventori awal (jika ada) yaitu jika suatu horison terdapat $\mathrm{n}$ periode.

$$
\text { TotalKapasitas }=\sum_{i=1}^{n}(L t+M t+I t)
$$

Jumlahkan total produksi selama periode yaitu:

$$
\text { Total Permintaan }=\sum_{t=1}^{n} Y t
$$

Dimana $\mathrm{Yt}=$ Permintaan pada periode $\mathrm{t}$ Jika total kapasitas lebih besar dari total permintaan maka harus dibuat permintaan fiktif dengan biaya nol (dummy). Bila total permintaan melebihi total kapasitas maka harus dibuat kapasitas dummy dengan biaya nol. Kenyataannya kapasitas atau permintaan dummy tidak akan pernah diproduksi.

4. Persiapkan sebuah matrik transportasi seperti dibawah ini. Matrik pada tabel 2.1 untuk formulasi masalah dengan horison sebesar 4 periode. Kolom pertama dan terakhir menunjukkan alternatif produksi yang tersedia tiap periode dan kapasitasnya. Kolom kedua sampai kelima, menunjukkan permintaan yang harus dipenuhi. Total permintaan per periode diletakkan pada baris terakhir 
yaitu : Y1,Y2,Y3 dan Y4. Tiap sel matriks berisi nilai-nilai $\mathrm{r}, \mathrm{v}$ dan seterusnya yang menunjukkan biaya persatuan produksi jika suatu permintaan dialokasikan ke sel tersebut.

5. Mengalokasikan permintaan tiap periode pada sel biaya terendah lebih dahulu. Pemilihan sel hanya pada sel-sel kolom produksi yang bersangkutan. Bila semua permintaan sudah dialokasikan maka langkah terakhir adalah menjumlahkan total produksi tiap periode (baris $2,3,4,5$ ) dan hasilnya menjadi rencana agregat untuk horison tersebut.

\section{METODOLOGI PENELITIAN}

Langkah-langkah yang dilakukan dalam penelitian ini meliputi :

1. Survey Perusahaan

Survey dilakukan untuk melihat dan mengamati secara langsung latar belakang dan permasalahan yang terjadi diperusahaan.

2. Perumusan masalah

Guna mengarahkan penelitian ini, maka ditetapkan terlebih dahulu rumusan masalah yang timbul berdasarkan latar belakang masalah

3. Studi literatur

Sebagai landasan dan kerangka dalam berfikir bagi penelitian yang akan dilakukan, maka penulis perlu menyertakan beberapa konsep atau teori yang mendukung penelitian.
4. Pengumpulan data

Data-data yang dikumpulkan adalah data primer berupa waktu proses produksi dan data sekunder perusahaan tentang historis permintaan, data penyimpanan, data biayabiaya dan data kalender kerja.

\section{Pengolahan Data}

Dari hasil perhitungan peramalan dengan menggunakan program MINITAB. Untuk selanjutnya digunakan metode Transportasi. Metode transportasi VAM, NCR, MODI.

7. Analisa Pembahasan

Berdasarkan hasil pengolahan data dilakukan analisa perbandingan biaya produksi sebelum dan sesudah perencanaan

8. Kesimpulan dan saran

Merupakan rangkuman hasil penelitian dalam kaitannya dengan arah tujuan penelitian yang ditetapkan.

Adapun data-data yang dikumpulkan dalam menyelesaikan permasalahan perencanaan penjadwalan produksi adalah:

1. Data Primer (hasil pengukuran langsung)

- data waktu proses tiap produk

2. Data skunder (data baku dari perusahaan)

- Sistem produksi perusahaan dan aliran proses produksi dari masingmasing produk.

- Jenis mesin dan data jenis produk.

- Data biaya-biaya produksi dan alternatif produksi.

- Data jumlah permintaan yang ada untuk tiap-tiap produk. 
Tabel 1

Data jenis produk

\begin{tabular}{|c|c|c|}
\hline Group Produk & Jenis Produk & $\begin{array}{c}\text { Kode } \\
\text { Produk }\end{array}$ \\
\hline $\begin{array}{l}\text { Pipa kelas AW } \\
\text { (tekanan kerja } \\
\left.10 \mathrm{~kg} / \mathrm{cm}^{2}\right)\end{array}$ & $\begin{array}{l}\text { PVC AW } 0,5 \text { inch } \\
\text { PVC AW } 0,75 \text { inch } \\
\text { PVC AW } 1 \text { inch } \\
\text { PVC AW } 1,25 \text { inch } \\
\text { PVC AW } 1,5 \text { inch } \\
\text { PVC AW } 2 \text { inch } \\
\text { PVC AW } 2,5 \text { inch } \\
\text { PVC AW } 3 \text { inch } \\
\text { PVC AW } 4 \text { inch } \\
\text { PVC AW } 5 \text { inch } \\
\text { PVC AW } 6 \text { inch } \\
\text { PVC D } 11 / 4 \text { " inch } \\
\text { PVC D } 11 / 4 \text { inch } \\
\text { PVC D } 2 \text { inch } \\
\text { PVC D } 11 / 4{ }^{\prime \prime} \text { inch } \\
\text { PVC D } 3 \text { inch } \\
\text { PVC D } 4 \text { inch } \\
\text { PVC D } 5 \text { inch } \\
\text { PVC D } 6 \text { inch }\end{array}$ & $\begin{array}{l}\text { AW 1/2" } \\
\text { AW 3/4" } \\
\text { AW 1" } \\
\text { AW } 11 / 4 " \\
\text { AW 11/2" } \\
\text { AW 2" } \\
\text { AW 21/2" } \\
\text { AW 3" } \\
\text { AW 4" } \\
\text { AW 5" } \\
\text { AW 6" } \\
\text { D } 11 / 4 " \\
\text { D } 11 / 2 " \\
\text { D 2" } \\
\text { D 2 1/2" } \\
\text { D 3" } \\
\text { D 4" } \\
\text { D 5" } \\
\text { D 6" }\end{array}$ \\
\hline
\end{tabular}

Tabel 2

\section{Komposisi Bahan Baku}

\begin{tabular}{|c|cc|c|}
\hline Nó & Nama Bahan & Jumiah \\
\hline 1. & Poly Vinil Clorida & $200 \mathrm{~kg}$ \\
2. & Additive yang terdiri dari : & $13 \mathrm{~kg}$ \\
& a. & Pewax & \\
& b. & Loxial $\mathrm{C}_{22}$ & \\
& c. & NLS & \\
& d. & Stearet Acid & \\
& e. & Tiona & \\
& f. & LH 50 & \\
g. & LT 03 & \\
& h. & LT 01 & \\
& i. & Calcium & \\
& & Carbonate & \\
& & (CaCo $)$ & \\
& &
\end{tabular}

Tabel 3

Data Alternatif Produksi

\begin{tabular}{|c|c|c|c|}
\hline No & $\begin{array}{c}\text { Alternatif } \\
\text { Produksi }\end{array}$ & $\begin{array}{c}\text { Kapasitas } \\
\text { (Jam/Org } \\
\text { /Hari) }\end{array}$ & $\begin{array}{c}\text { Biaya } \\
\text { (Rp/Jam } \\
\text { /Hari) }\end{array}$ \\
\hline 1. & Regular Time & 8 & 1500 \\
2. & Over Time & 3 & 3000 \\
3. & Inventory & - & $50 /$ unit \\
\hline
\end{tabular}

\section{HASIL DAN PEMBAHASAN}

\section{Peramalan}

Peramalan disini memakai program MINITAB menggunakan tiga metode peramalan yang sesuai yaitu

1. Motode Moving Average.

2. Motode Single Eksponensial Smoothing

3. Motode Double Eksponensial Smoothing

Dalam pemilihan metode peramalan, di sini menetapkan metode peramalan dengan nilai MAPE terkecil atau metode peramalan yang memiliki nilai MAPE $<10 \%$.

\section{Tabel 4}

\section{Model Peramalan Terpilih dengan}

MAPE Terkecil

\begin{tabular}{|c|c|c|c|c|}
\hline \multirow[b]{2}{*}{ No } & \multirow[b]{2}{*}{$\begin{array}{c}\text { Jenis } \\
\text { Produk }\end{array}$} & \multicolumn{3}{|c|}{ MAPE } \\
\hline & & $\begin{array}{l}\text { Moving } \\
\text { Average }\end{array}$ & $\begin{array}{c}\text { Single } \\
\text { Exponential } \\
\text { Smoothing }\end{array}$ & \begin{tabular}{|c|} 
Double \\
Exponentia \\
Smoothing
\end{tabular} \\
\hline 1 & AW 1/2" & 19 & 9 & 10 \\
\hline 2 & $\mathrm{AW} 3 / 4 "^{3}$ & 18 & 9 & 10 \\
\hline 3 & $\mathrm{AW} 1^{"}$ & 17 & 9 & 6 \\
\hline 4 & $\mathrm{AW} 11 / 4 "$ & 12 & 6 & 5 \\
\hline 5 & AW $11 / 2 "$ & 7 & 5 & 2 \\
\hline 6 & AW 2" & 11 & 6 & 4 \\
\hline 7 & AW $21 / 2 "$ & 8 & 5 & 3 \\
\hline 8 & AW 3“ & 7 & 5 & 2 \\
\hline 9 & AW 4" & 14 & 8 & 4 \\
\hline 10 & AW 5" & 7 & 4 & 2 \\
\hline 11 & AW 6" & 9 & 8 & 4 \\
\hline 12 & D $11 / 4 "$ & 9 & 8 & 4 \\
\hline 13 & D $1 \frac{1 / 2}{}{ }^{*}$ & 9 & 5 & 4 \\
\hline 14 & D 2" & 11 & 6 & 5 \\
\hline 15 & D $21 / 24$ & 6 & 4 & 2 \\
\hline 16 & D 3" & 8 & 5 & 3 \\
\hline 17 & D 4" & 7 & 5 & 3.3 \\
\hline 18 & D 5" & 9 & 6 & 2.5 \\
\hline 19 & D 6" & 8 & 5 & 1.8 \\
\hline
\end{tabular}


Adapun hasil peramalan di atas adalah sebagai berikut :

perencanaan dengan model peramalan terpilih

Tabel 5

Hasil Peramalan (dalam unit)

\begin{tabular}{|c|c|c|c|c|}
\hline AW $1 / 2 "$ & 158252 & 158252 & 158252 & 158252 \\
\hline $\mathrm{AW} 3 / 4 "$ & 155759 & 155759 & 155759 & 155759 \\
\hline $\mathrm{AW} \mathrm{l}^{*}$ & 23440 & 24815 & 26189 & 27564 \\
\hline AW $11 / 4 "$ & 96287 & 100861 & 105435 & 110009 \\
\hline AW $11 / 2 "$ & 20617 & 21214 & 21811 & 22408 \\
\hline AW 2“ & 12503 & 13044 & 13585 & 14126 \\
\hline AW $21 / 2^{45}$ & 80990 & 83680 & 86369 & 89059 \\
\hline AW 3“ & 14691 & 15119 & 15546 & 15974 \\
\hline AW 4" & 11589 & 12159 & 12750 & 13340 \\
\hline AW 5" & 13178 & 13593 & 14008 & 14423 \\
\hline AW 6" & 12507 & 12972 & 13437 & 13903 \\
\hline D $11 / 4 "$ & 95438 & 98935 & 102431 & 105928 \\
\hline D $11 / 2^{*}$ & 133029 & 137884 & 142739 & 147594 \\
\hline D 2" & 13409 & 13990 & 14571 & 15152 \\
\hline D $21 / 2{ }^{*}$ & 62882 & 64510 & 66198 & 67886 \\
\hline D 3" & 15519 & 16040 & 16560 & 17080 \\
\hline D 4" & 8193 & 8453 & 8713 & 8974 \\
\hline D 5" & 13187 & 13683 & 14179 & 14676 \\
\hline D 6" & 13331 & 13764 & 14197 & 14630 \\
\hline
\end{tabular}

\section{Rencana Agregat}

Adapun hasil rencana agregat tersebut adalah sebagai berikut :

Tăbel 6

\section{Total produksi hasil rencana agregat}

\begin{tabular}{|c|c|c|}
\hline \multirow{2}{*}{ Periode } & \multicolumn{2}{|c|}{ Total Produksi (At) } \\
\cline { 2 - 3 } & Regular & Overtime \\
\hline $\mathbf{1}$ & 43588 & \\
\hline $\mathbf{2}$ & 41032 & \\
\hline $\mathbf{3}$ & 45975 & \\
\hline $\mathbf{4}$ & 42816 & \\
\hline $\mathbf{5}$ & 46384 & \\
\hline $\mathbf{6}$ & 46384 & 192 \\
\hline
\end{tabular}

\section{Perencanaan Disagregat}

Berdasarkan pada pengolahan data, maka untuk perencanaan disagregat dalam penyusunan Jadwal Induk Produksi adalah sebagai berikut :

Tabel 7

Jadwal Induk Produksi

\begin{tabular}{|c|c|c|c|c|c|c|}
\hline \multirow{2}{*}{ Jenis } & \multicolumn{5}{|c|}{ PERIODE } \\
\cline { 2 - 7 } & $\mathbf{1}$ & $\mathbf{2}$ & $\mathbf{3}$ & $\mathbf{4}$ & $\mathbf{5}$ & $\mathbf{6}$ \\
\hline AW 1/2 “ & 6136 & 6136 & 7064 & 5208 & 6562 & 5710 \\
\hline AW 3/4 “ & 6233 & 6233 & 6233 & 6233 & 6233 & 6233 \\
\hline AW 1“ & 1005 & 1061 & 2292 & 0 & 1230 & 1287 \\
\hline AW 1 1/4 “ & 4066 & 4252 & 4437 & 4622 & 4807 & 4993 \\
\hline AW 1 1/2” & 915 & 939 & 964 & 989 & 1013 & 1038 \\
\hline AW 2“ & 554 & 577 & 600 & 623 & 646 & 669 \\
\hline AW 2 1/3 “ & 3702 & 3816 & 3931 & 4046 & 4160 & 4275 \\
\hline AW 3“ & 672 & 690 & 709 & 727 & 745 & 763 \\
\hline AW 4” & 529 & 553 & 579 & 605 & 630 & 656 \\
\hline AW 5” & 657 & 677 & 696 & 716 & 736 & 756 \\
\hline AW 6” & 710 & 733 & 756 & 779 & 802 & 825 \\
\hline D 1 1/4 “ & 4555 & 4719 & 4882 & 5046 & 5209 & 5372 \\
\hline D 1 1/2 “ & 5900 & 6106 & 6312 & 6519 & 6725 & 6931 \\
\hline
\end{tabular}




\begin{tabular}{|c|c|c|c|c|c|c|}
\hline D 2" & 680 & 708 & 737 & 766 & 795 & 823 \\
\hline D 2 1/2 " & 2992 & 3065 & 3141 & 3216 & 3292 & 3368 \\
\hline D 3" & 742 & 766 & 789 & 813 & 837 & 860 \\
\hline D 4” & 841 & 1 & 439 & 451 & 463 & 475 \\
\hline D 5” & 1357 & 0 & 713 & 736 & 758 & 781 \\
\hline D 6” & 1342 & 0 & 701 & 721 & 741 & 761 \\
\hline Total & 43588 & 41032 & 45975 & 42816 & 46384 & 46576 \\
\hline
\end{tabular}

Dari tabel diatas, dapat dianalisa bahwa untuk Jadwal Induk Produksi yang dihasilkan dari rencana disagregat ini merupakan patokan perusahaan dalam memproduksi produknya agar tidak terjadi kekurangan ataupun kelebihan produksi yang terlalu besar

\section{Analisa Biaya}

Hasil perbandingan biaya sebelum dan sesudah perencanaan selama 6 periode adalah sebagai berikut :

\section{Biaya Sebelum Perencanaan}

Biaya sebelum menggunakan perencanaan adalah: Rp. 437.016.000,-

\section{Biaya Setelah Perencanaan}

Selanjutnya agar permintaan tersebut dapat terpenuhi dengan biaya minimal perlu dilakukan penambahan tenaga kerja, penambahan tenaga kerja yang dibutuhkan sesuai dengan perencanaan yang telah dilakukan adalah sebanyak 23 orang. Kemudian dari hasil pengolahan dengan perencanaan yang baru menggunakan metode transportasi VAM diperoleh hasil sebagai berikut :

$$
=\text { Rp. } 405 . .250 .720,-
$$

Sedangkan pengolahan dengan metode NCR dan MODI mempunyai hasil yang sama dengan metode VAM (Rp.405.250.720,-), dari kedua metode tersebut hanya berbeda dalam tahap penyelesaian. Hasil dari kedua metode tersebut dapat dilihat pada lampiran.

Dari hasil perencanaan menggunakan metode yang baru diperoleh penghematan sebagai berikut:

Penghematan

$=\operatorname{Rp} 437.016 .000,-\operatorname{Rp} .405 .250 .720,-$

$=$ Rp. 31.765.280,-

\section{KESIMPULAN}

Berdasarkan hasil pengolahan data dapat diambil kesimpulan sebagai berikut :

1. Rencana Agregat

Tabel 8

Rencana agregat

\begin{tabular}{|c|c|c|}
\hline \multirow{2}{*}{ Periode } & \multicolumn{2}{|c|}{ Total Produksi (At) } \\
\cline { 2 - 3 } & Regular & Overtime \\
\hline $\mathbf{1}$ & 43588 & \\
\hline $\mathbf{2}$ & 41032 & \\
\hline $\mathbf{3}$ & 45975 & \\
\hline
\end{tabular}




\begin{tabular}{|l|l|l|}
\hline $\mathbf{4}$ & 42816 & \\
\hline $\mathbf{5}$ & 46384 & \\
\hline $\mathbf{6}$ & 46384 & 192 \\
\hline
\end{tabular}

2. Jadwal Induk Produksi

Jadwal induk produksi untuk masing-masing produk adalah:

Tabel 9

Jadwal Induk Produksi

\begin{tabular}{|c|c|c|c|c|c|c|}
\hline \multirow{2}{*}{$\begin{array}{c}\text { Jenis } \\
\text { produksi }\end{array}$} & \multicolumn{6}{|c|}{ Periode } \\
\hline & 1 & 2 & 3 & 4 & 5 & 6 \\
\hline AW $1 / 2$ “ & 6136 & 6136 & 7064 & 5208 & 6562 & 5710 \\
\hline AW $3 / 4$ “ & 6233 & 6233 & 6233 & 6233 & 6233 & 6233 \\
\hline AW 1“ & 1005 & 1061 & 2292 & 0 & 1230 & 1287 \\
\hline AW 1 1/4" & 4066 & 4252 & 4437 & 4622 & 4807 & 4993 \\
\hline AW 1 1/2" & 915 & 939 & 964 & 989 & 1013 & 1038 \\
\hline AW 2“ & 554 & 577 & 600 & 623 & 646 & 669 \\
\hline AW $2 \frac{1}{2} "$ & 3702 & 3816 & 3931 & 4046 & 4160 & 4275 \\
\hline AW 3“ & 672 & 690 & 709 & 727 & 745 & 763 \\
\hline AW 4" & 529 & 553 & 579 & 605 & 630 & 656 \\
\hline AW 5" & 657 & 677 & 696 & 716 & 736 & 756 \\
\hline AW 6" & 710 & 733 & 756 & 779 & 802 & 825 \\
\hline D $11 / 4$ “ & 4555 & 4719 & 4882 & 5046 & 5209 & 5372 \\
\hline D $11 / 2 *$ & 5900 & 6106 & 6312 & 6519 & 6725 & 6931 \\
\hline D 2" & 680 & 708 & 737 & 766 & 795 & 823 \\
\hline D $21 / 2$ “ & 2992 & 3065 & 3141 & 3216 & 3292 & 3368 \\
\hline D 3" & 742 & 766 & 789 & 813 & 837 & 860 \\
\hline D 4" & 841 & 1 & 439 & 451 & 463 & 475 \\
\hline D 5” & 1357 & 0 & 713 & 736 & 758 & 781 \\
\hline D 6" & 1342 & 0 & 701 & 721 & 741 & 761 \\
\hline Total & 43588 & 41032 & 45975 & 42816 & 46384 & 46576 \\
\hline
\end{tabular}

1. Kalkulasi Biaya

Setelah dilakukan analisa biaya diperoleh penghematan biaya sebesar :

Rp. 31.765 .280 ,-
Prosentase penghematan yang terjadi adalah:

$=7.27 \%$ 


\section{DAFTAR PUSTAKA}

Bethworth, David D. and Bailey, James E., 1982, Integrate Production Control System, New york, John Wiley and Sons Inc.

Gerald Keller, Brian Warrack, 2000, Statistics

For Management And economics,

Fifth Edition, Duxbury Thomson Learning,

Hamid Noori, Russell Radford, 1995, Production And Operation Management, Total Quality And Responsiveness, McGraw - Hill Inc.
Lincolin Arsyad, 1994 , Peramalan Bisnis, Edisi I, BPFE Yogyakarta.

Richard Bronson, Hans J. Waspakrik, 1991, Teori Dan Soal-Soal Operasional Research, Seri Buku Schaum's, Erlangga,

Seetharama L. Narasimhan, Dennis W Mcleavey, Peter J. Billington, University Of Rhode Sland, 1995, Production Planning And Inventory Control, The United State Of Amerika Subagyo Pangestu, 1991., T. Hani Handoko, Marwan Asri, Dasar-dasar Operation Research, Edisi II, BPFE, Yogyakarta. 